Working Paper No. 624, 2004

Commercialization of Patents and External Financing during the R\&D-Phase

by Roger Svensson

IUI, The Research Institute of Industrial Economics

P.O. Box 5501

SE-114 85 Stockholm

Sweden 


\title{
Commercialization of Patents and External Financing during the R\&D-Phase
}

\author{
Roger Svensson * \\ The Research Institute of Industrial Economics (IUI), \\ Box 5501, S-11485 Stockholm, Sweden \\ rogers@iui.se
}

June 2004

Key words: Patents, R\&D, commercialization, external financing, survival models.

JEL Classification: O31, O38, G30, M13.

\begin{abstract}
Using a unique database on individual Swedish patents, a survival model estimates how different factors influence the time it takes until commercialization starts. To the best of my knowledge, such an analysis has not been undertaken before. For external financing of patent projects and small technology-based firms, Sweden has during long time relied on government support rather than private venture capital firms. The empirical results show that the larger share of the patent-owners' costs during the R\&D-phase that are covered by government financial support, the longer time it takes until the patents are commercialized. It seems like the government financing creates a pool of patents with bad perspectives of commercialization. The reasons to the bad performance are: 1) the design of the government loans, where the patent owner can escape from paying back the loan if the project failures; and 2) the competence and incentives of the government institutions, which are not profit maximizing. A policy implication is therefore that the government should either change the conditions of the loans or, preferably, stop acting as a venture capital firm. The government should instead facilitate private solutions and the growth of private venture capital firms.
\end{abstract}

* The author would like to thank Lars Persson, IUI, and Erik Mellander, IFAU, for constructive comments, as well as Jakob Eliasson for collection of, and work with, the database. 


\section{Introduction}

It is well known that innovations are crucial for economic growth. The ultimate value of an innovation is the increase in economic value it creates. In order to understand the factors important for innovations, empirical studies have evaluated how different factors affect the number of granted patents. However, many patents are not commercialized and will not contribute to economic welfare. Thus, by using patents as measure, wrong conclusions might be drawn. More precisely, the purpose of this study is to analyze which factors are important for the choice to commercialize patents. The term commercialization means that the owners of the patent have taken measures with the purpose to generate incomes from the patent. ${ }^{1}$ Patents rather than inventions are here chosen as the unit of observation, because the former are much easier to identify and follow.

In the empirical analysis, a unique database of Swedish patents granted to medium-sized and small firms as well as individuals is used. Here, information about individual patents has been collected, for example, the place where the invention behind the patent was created, the ownership of the inventors, the financing during the R\&Dphase, whether the patent has been commercialized or not, etc. By using survival analysis, it is then statistically tested how different explanatory factors influence the time it takes until patents are commercialized. To the best of my knowledge, such a statistical survival analysis on the choice to commercialize patents has never been done earlier.

Sweden is one of the countries in the world that spends most resources on R\&D compared to GDP - both totally and at the universities (SOU 1996:70). At the same time, Sweden is top-ranked with respect to publications in international academic journals in relation to GDP (National Science Board, 1997), and granted patents per capita (EU, 2001). On the other hand, there are not so many small technology-based fast-growing firms in Sweden, which use the knowledge and innovations created by the R\&D. The commercialisation of the patents and the intellectual capital seems not to be so efficient in Sweden (Utterback and Reitberger, 1982; Rickne and Jacobsson, 1996, 1999; Goldfarb and Henrekson, 2001). A comparison can be made with the U.S., which also spend a lot of resources on R\&D. However, the U.S. has had many small firms,

\footnotetext{
${ }^{1}$ There are several commercialization modes, for example, commercialization in a new or existing firm, licensing the patent or selling the patent.
} 
which - by basing their competitiveness on innovations - have grown large in sectors like medicine, microbiology, IT and electronics.

During the last decade, there has been a debate in Sweden whether lack of venture capital and external financing for entreprenuers and inventors restarains economice growth and development of small technology-based firms (Braunerhjelm, 1999; Karaömerlioglu and Jacobsson, 2000). Since investments in technology projects often are characterized by assymetrical information for insiders and outsiders, focus in the debate has also been on whether the external financiers are competent or not. In contrast to the U.S. where the external financing is private, firms have since long time been financially supported by the government in Sweden. Some government institutions and foundations assist also individuals and small firms with financing of patent projects - especially during the early part of the projects (R\&D-phase) before the commercialization starts. The assistance takes the form of grants or favorable loans. These loans do not need to be repaid if the project failures, and if commercialization are undertaken then the repayment is connected to the turnover. In the present study, I argue that these conditions create moral hazard problems, because there are few incentives for the patent owners to continue with commercialization. Therefore, I will especially analyze how different financing alternatives during the R\&D-phase affect the choice to commercialize patents.

The paper is organized as follows. Previous studies about commercialization of patents and adequate theories are discussed in section 2 . In section 3 , the database and basic statistics are described. The statistical model and hypotheses are set up in section 4. In section 5, the empirical estimations are shown, and the final section concludes.

\section{Previous studies and theoretical discussion}

\subsection{Previous studies}

Most previous studies analyzing patents use data from one or several national patent offices. This means that the researchers do not know whether the patents have been commercialized or not. Patent databases with detailed information (which are not available from the national patent offices) have seldom been collected earlier. The few previous studies with such databases have focused on estimating the profits from patenting rather than analyzing problems related to the commercialization (Rossman 
and Sanders, 1957; Sanders et al., 1958; Sanders, 1962, 1964; Schmookler, 1966; Cutler, 1984; SRI International, 1985).

Other studies of commercialization of inventions have mostly used technology offices in connection to universities, government laboratories (Jaffe and Lerner, 2001) or the firm (Utterback and Reitberger, 1982, Olofsson and Wahlbin, 1993; Rickne and Jacobsson, 1996, 1999; Lindholm-Dahlstrand, 1997a, 1997b; Cohen et al., 2000) as the unit of observation and then specifically start-up firms, although a majority of the patents and inventions probably are commercialized in existing firms. In the US, for example, $90 \%$ of the patents are commercialized in already existing firms (AUTM, 1998). Furthermore, the interesting question is not whether inventions and patents lead to new firms, but whether they translate into a higher standard of living.

Morgan et al. (2001) describe the commercialization rate of American patents across different groups. Industrial patents had a commercialization rate of $48.9 \%$, whereas inventors in the education sector had a rate of $33.5 \%$. However, the authors never try to relate this commercialization rate to other explanatory factors and do not run any survival model - perhaps due to lack of data.

\subsection{Theoretical discussion}

Patents, like R\&D-projects, are typically characterized by high costs and no incomes in the early R\&D-phase, and high uncertainty about future incomes. Apart from technological problems, lack of financial resources is one of the largest problems during the R\&D-phase. In the later commercialization phase, several complementary resources are needed, e.g., financing, marketing and manufacturing capabilities. Large firms have these complementary capabilities as well as information about the market. Small firms have these resources in-house to a lower degree and individuals have none of these capabilities. Thus, large and small firms as well as indivduals have completely different conditions under which they commercialize their inventions. It is therefore likely that external financing and advices are needed by individuals and to some degree also by small firms.

Clearly, the inventors have more knowledge about the invention / patent than potential external financiers. Thus, problems with asymmetrical information and adverse selection are present. The search and transaction costs to find interesting projects and to evaluate the technical and commercial potential are in other words large for external financiers. It is especially difficult to make this evaluation in the R\&D- 
phase, when the uncertainty about the project is very high. The Swedish government has during long time intervened on the market for external financing, because it has been claimed that there are market imperfections. However, this does not need to be true, because private PVC-firms exist private market solutions work well in other countries, e.g., in the U.S.

Among the Swedish government institutions, SIC and NUTEK almost purely assist with financial resources during the R\&D-phase, whereas ALMI enters when it is time for commercialization. ${ }^{2}$ An inventor can during the R\&D-phase apply for grants from SIC. These grants can be used to cover patent costs, which sometimes are very high. The application costs for a Swedish patent are around 3-5,000 Euro, but for a patent covering Europe they are around 25-50,000 Euro. A further step for SIC is to lend capital to the inventors. A typical SIC-loan is designed in the following way. The borrower pays a subsidized interest rate and begins to pay back the loan some years after the commercialization has started, but if there is no commercialization, then there is a possibility that the borrower does not need to pay pack the loan at all. NUTEK lends money to a subsidized interest rate primarily to firms during the $R \& D$-phase (although grants are also possible). Similarly to SIC, these loans can wholly or partly be written off after some years, if the commercialization fails or turns out to be less successful than expected. ${ }^{3}$

Even more interesting is what happens if the borrower does receive incomes during the commercialization. The repayment of the loan is then connected to the turnover. This means that projects, which have a low or medium expected profit-level, will probably not be commercialized at all, since the repayment of the loan would then erase the whole profit. However, this will not stop the commercialization if the expected profit-level is high. Due to the design of the loans assisted by the government institutions, it is likely that there exist problems related to moral hazard. The inventors, who have received loans from the government, do not need to care about further commercialization of the patent, since they know that there is a high probability that they do not need to pay back the loans at all. If the expected profit of the project is of mediocre size, the incentives to continue the commercialization are low, since the

\footnotetext{
${ }^{2}$ In contrast to ALMI, SIC has no local offices in Sweden. Therefore, ALMI evaluates many local patent projects and decide whether loans from SIC will be approved. SIC was winded up in 2003, but similar loans are since 2003 offered by ALMI.

${ }^{3}$ In $2004,60 \%$ of the SIC-loans had been lent to projects that had failed. In the case of NUTEK, $50 \%$ of the borrowers pay back at least parts of the loans, whereas $1 / 3$ of the lent money is paid back.
} 
repayment is connected to the turnover rather than the profit. It is often better to exit the project, escape from paying back the loans and start a new project.

Private venture capital (PVC) firms and private persons (business angels), who assist with financing during the R\&D-phase, own shares in the patent project / firm. The repayment is then connected to the profit when the patent is commercialized. In contrast to the projects financed by the government, this means that even if the expected profit is of mediocre size, the inventors have incentives to undertake a commercialization.

Furthermore, the government financing institutions do not maximize the profit. Their employed administrators have therefore few incentives to search for really good patent projects to lend money to. On the other hand, PVC-firms and business angels are profit maximizing. It is therefore more likely that they are more careful than government institutions in which patent projects they invest and that they have a more active, and advisory, role already during the R\&D-phase. The PVC-firms not only provide financial capital, but also networks and competence in terms of knowledge about the market, marketing, juridical assistance, etc. An inventor or firm, which has received contacts and financing during the R\&D-phase from a PVC-firm or business angel, should easier receive financing and advice during the commercialization phase.

\section{Database and descriptive statistics}

In order to analyze commercialization of patents, it is necessary to have a detailed database about individual patents. ${ }^{4}$ In a previous pilot study (Svensson, 2002), most patents were commercialized within 5 years after they had been applied. Therefore, the year of 1998 is chosen for the current database. In 1998, 2760 patents were granted in Sweden. Of these, 776 were granted to foreign firms, 902 to large Swedish firms with more than 1000 employees, and 1082 to Swedish individuals and firms with less than 1000 employees. Information about inventors, applying firms and their addresses for each patent was bought from the Swedish Patent and Registration Office (PRV). Thereafter, a questionnaire was sent out to the inventors of the patents. ${ }^{5}$ In the pilot

\footnotetext{
${ }^{4}$ All inventions do not result in patents. However, as an invention, which does not result in a patent, is not registered anywhere, there are two problems to empirically analyze the invention rather than the patent. Firstly, it is impossible to find these new ideas, products and developments among all firms and individuals. On the other hand, all patents are registered. Secondly, even if one finds the "inventions", it is difficult to judge whether they are enough improvements to be called inventions or not. Only the national and international patent offices make such judgements. Therefore, the choice of the patent rather than the invention is the only alternative for an empirical study of the commercialization process.

${ }^{5}$ Each patent has always at least one inventor and often also an applying firm. The inventors or the applying firm can be the owner of the patent, but the inventors can also be owners of the patent indirectly,
} 
survey carried out in 2002, it turned out that large Swedish firms refused to give information about individual patents. Furthermore, it is impossible to persuade foreign firms to fill in questionnaires about patents. These firms are almost always large multinationals firms. Therefore, the population consists of 1082 patents granted to Swedish individuals and firms with less than 1000 employees.

In the questionnaire, we asked the inventors about the work place where the invention was created and the financing of the invention during the $R \& D$ phase, whether the invention had been commercialized, which kind of commercialization mode was chosen, how the commercialization was financed, about the inventors' incomes and profits from the patent, and if there were any problems with the commercialization alternatively why the patent never was commercialized. As many as 867 of the inventors filled in and returned the questionnaire, i.e., the response rate was $80 \%$ ( 867 of 1082). This response rate is satisfactorily high, if one takes into account that such a database has seldom been collected before and that the inventors or the applying firms usually consider information about inventions and patents secret.

The application year of the 867 patents is described as light-gray staples in Figure 1. 85\% of the patents were applied between 1994-97. In 2003, 537 of these patents $(61 \%)$ had started commercialization. The starting year of the commercialization are represented by dark staples, which almost follow a normal distribution. Although the last year of observation is 2003, it is not likely that many of the 330 noncommercialized patents will be commercialized after 2003.

The 867 patents and the commercialization rate are described across firm groups and ownership in Table 1. As many as 408 patents (47\%) were granted to individual inventors, and 116, 201, 142 patents were granted to medium-sized firms (101-1000 employees), small firms (11-100 employees) and close companies (2-10 employees). The commercialization rate of the firm groups is between 66 and 74\%, whereas the rate of the individuals is not higher than $52 \%$. A contingent-table test suggests that there is a significant difference in the commercialization rate between firms and individuals. The chi-square value is 30.55 (with 3 d.f.), significant at the 1 percent level. In the lower part of Table 1, it is shown that the commercialization rate is lower if the inventors are owner of the patent. The chi-square value is 4.43 (with 1 d.f.), significant at the 5\%-

via the applying firm. Sometimes the inventors are only employed in the applying firm, which owns the patent. If the patent had more than one inventor, then the questionnaire was sent only to one inventor. 
level. However, the ownership is closely related to the firm size, the larger the firm size, the lower share of the patents is (directly or indirectly) owned by the inventors.

[Table 1]

In Table 2, the commercialization rate is related to external financing during the R\&D phase. Patents with external financing during the R\&D-phase have a significantly lower commercialization rate than those that have not. When dividing the external financing on different sources, the commercialization rate is significantly lower only for patents supported by government funds. ${ }^{6}$ However, it is neither shown when the commercialization started nor how large share of the R\&D that was financed with government or private capital. Such a survival analysis will be undertaken in the statistical part.

[Table 2]

\section{Statistical model and hypotheses}

\subsection{Statistical model}

Since the analysis focuses on an "event" to occur, survival (duration) analysis is used in the statistical estimations. The event is here that the patent has been commercialized, and it is also measured when this commercialization started. Preliminary in the empirical analysis, a survival distribution function and a Hazard function will be estimated and plotted. The survival function, $S(t)$ in equation 1, shows how large share of the patents that survive beyond a time point $t$. The Hazard function, $h(t)$ in equation 2 , shows the conditional probability that a patent will be commercialized in a specific time period $\Delta t$, given that it has "survived" (not been commercialized) until the beginning of $t$. The Hazard can also be expressed as a function of the probability density function, $f(t)$, and the survival function.

\footnotetext{
${ }^{6}$ In the group with other external financing, the financing might be government or private, but the intention with the financing is not to finance a patent application / project, but rather research in general. Here, the inventors often use the resources to the patent without the financers' (mostly a university) knowledge about this. Therefore, this kind of financing is regarded as passive. In contrast, the government and private groups represent active financing, where the financier support, or invest in, a specific patent.
} 


$$
\begin{aligned}
& S(t)=\operatorname{Pr}(T>t)=1-F(t) \\
& h(t)=\frac{f(t)}{S(t)}=\lim _{\Delta t \rightarrow 0} \frac{\operatorname{Pr}(t \leq T<t+\Delta t \mid T \geq t)}{\Delta t} .
\end{aligned}
$$

In the main empirical analysis, it is estimated how different explanatory factors affect the survival time of the patents. The dependent variable, $T_{i}$, is a random variable showing how many years it takes until commercialization started for patent $i$, measured from the time point of patent application. Most patents in the database were applied between 1994-97 and the end point of observation in the dataset is 2003. Patents that have not yet been commercialized in 2003 are "right-censored" (337 observations). If the owners have started the commercialization before they applied for the patent, then the patents are "left-censored" (37 observations). The measurement of the starting point of commercialization in years is a rather rough measure. Therefore, $T$ is "intervalcensored" for those patents, which were commercialized after the patent application occurred and not later than 2003, i.e. the rest of the patents (493 observations). If the patent is commercialized within the first year, $T$ gets an interval-censored value between 0.1 and 1 , within the second year $T$ is between 1.1 and 2 , etc.

Since both left-censored and interval-censored observations are included, the most popular survival model, the Cox (1972) survival model, cannot be used. ${ }^{7}$ Instead the accelerated failure time (AFT) model is the appropriate statistical model (Allison, 1995):

$$
\log \left(T_{i}\right)=\beta_{0}+\beta_{1} x_{i 1}+\beta_{2} x_{i 2}+\ldots \ldots+\beta_{k} x_{i k}+\sigma \varepsilon_{i}
$$

where $\varepsilon$ is a random disturbance term, the $\beta$ s and $\sigma$ are parameters to be estimated, and the $x^{\prime}$ s are explanatory variables. The $\varepsilon^{\varsigma}$ s can have various distributions, corresponding to different AFT-models, e.g., the log-normal, log-logistic, exponential, Weibull and gamma models. In the empirical part, all of these models will be run. By using likelihood-ratio tests, it is possible to decide which of the models that fits the data best.

\footnotetext{
${ }^{7}$ The fact that there are left- and interval-censored observations is also the reason why a usual logit survival model cannot be used.
} 


\subsection{Hypotheses}

Turning to the explanatory variables, such factors are included that are expected to affect: 1) the time it takes to commercialize the patent (survival time); or 2) the probability that patent will be commercialized at all. Basic statistics and hypotheses of these factors are described in Table 3, and correlations are shown in Appendix Table A1. When interpreting the sign of the hypotheses in Table 3, it is important to remember the definition of equation (3). A positive parameter estimate means that the survival time increases (or in other words that the conditional probability of commercialization decreases) when the explanatory variable gets a higher value.

Other factors that are specific for the commercialization, e.g., commercialization mode (licensing, new company, selling the patent, etc.), financing during the commercialization or whether the inventors are active or passive during the commercialization, are not included in the estimations, since they cannot be measured for non-commercialized patents.

It is expected that firms, which have marketing, manufacturing and financial resources in-house, have better possibilities to commercialize their patents compared to individuals. FIRM1 is a dummy that takes on the value of 1 for medium-sized firms with 101-1000 employees, and 0 otherwise. FIRM2 equals 1 for small firms with 11100 employees, and 0 otherwise. Finally, FIRM3 is a third dummy taking the value of 1 for close companies with 2-10 employees, and 0 otherwise. Thus, the firm dummies are here related to the reference group of individual inventors. Therefore, the parameter estimates are expected to be negative, implying a shorter "survival" time of the patents and a higher probability that the patents will be commercialized. Which of the three dummies that has the highest value is difficult to predict. It is true that large firms have more resources available for a commercialization, but it is not clear that larger firms are more likely to commercialize patents than smaller firms. Previous studies have, for example, shown that large multinational firms tend to patent more inventions ("shadow patents") in order to protect other patents (Cohen et al., 2000).

As discussed above, the Swedish government institutes, which assist with financing of patent projects, have a curious design of their loans. The borrower can escape from paying back the loan if the patent is not commercialized. If the patent is commercialized, repayment is connected to the turnover rather than the profit. This means that the expected profit of a commercialization must be higher than a threshold value - otherwise the repayment will erase the profit. It is therefore likely that the 
government financing during the $\mathrm{R} \& \mathrm{D}$ phase will create moral hazard problems. The loan conditions will attract inventors, who own inventions with no perspectives of commercialization, and will deter many good patents from being commercialized, because the expected profit level is not high enough. GOVFIN measures how large share of the patent's $R \& D$-costs (in percent) that was financed through government capital. ${ }^{8}$ A positive influence on the survival time is expected.

In a similar way, the variable PRIVFIN shows how many percent of the R\&D costs that were financed through external private venture capital. Private venture capitalist can be regarded as strict profit maximizing and they only invest in projects they believe in. The external financiers should therefore push harder for that the patents will be commercialized and create incomes. It is also likely that patents that had external private financing during the $R \& D$ phase, have more easy to attract external venture capital (from the same private venture capitalists) during the commercialization phase. Therefore, a negative effect of PRIVFIN on the survival time is expected.

There is also a third kind of external financing. OTHERFIN measures how large share of the R\&D costs, which was financed through universities and research foundations. Typically, patents created at universities have this kind of external financing. The intention of this financing is not to assist a patent project, but rather to finance R\&D in general. The financiers have, however, no control of what the resources actually are used for. It is difficult for the inventors to use the resources for patent applications, but more easy to hide labor costs necessary for creating the invention within this financing. A problem with this kind of financing is that it cannot be used for commercialization. Consequently, the inventors stand often alone without financing when considering commercialization. A positive parameter estimate is therefore expected.

Basic research is relatively more common at universities. It is then likely that university patents also are more related to basic research and have a lower probability of commercialization (Jaffe and Lerner, 2001). In contrast to the U.S., the university researchers in Sweden are wholly owners of their patents. The Swedish universities have no ownership and consequently no interest in that employed researchers commercialize their patents. The dummy UNIV, which equals 1 for university patents, is therefore expected to have a positive influence on the survival time.

\footnotetext{
${ }^{8}$ Patent application costs are included in the R\&D costs.
} 
OWNER shows how large share (in percent) of the patent that the inventors own directly or indirectly. If the inventors, who have the technological knowledge of the patent, also are owners of the patent, they should have larger incentive to work harder for a commercialization. A negative parameter estimate on the survival time is therefore expected.

MOREPAT is an additive dummy, which equals 1 if the inventors or the applying firm have more competitive patents in the same technology area and 0 otherwise. To apply for many similar patents is a strategy often chosen by owners especially large firms - who want to protect a main patent. These extra patents are called shadow patents and are seldom commercialized. However, many patents can also be an indication of that the owners have more knowledge and experience of the area, and should therefore increase the probability of commercialization. Therefore, the impact on the survival time is unsettled. Finally, INVNMBR is here the number of inventors of the patent.

It is likely that different technologies are connected with different risks. Consequently, the technology class can affect the survival time and conditional probability that a patent will be commercialized. The patents are divided in 30 technology groups according to Breschi et al. (2004). These groups are based on the patents' main IPC-Class. However, all technology groups are not represented in the dataset and some groups have too few observations. Therefore, only 26 groups and 25 additive dummies are used in the present study. ${ }^{9}$

The data is divided into six different kinds of regions according to NUTEK (1998): Large-city regions, university regions, regions with important primary city centers, regions with secondary city centers, small regions with private employment, and small regions with government employment. Five additive dummies are included in the estimations for these six groups.

Additive dummies are also included for different application years, since the level on the business cycle may affect when and whether a patent will be commercialized. The data has five application year periods (1985-90, 1991-92, 1993-94, 1995-96, 1997-98) and four additive dummies are assigned for these periods. ${ }^{10}$

\footnotetext{
${ }^{9}$ The technology classes with too few observations are instead merged together with other classes, which are closely related (Breschi et al., 2004).

${ }^{10}$ Preliminary, time dummies for individual application years were used. But one of the models (the gamma model) did not converge by some reason. Therefore, time dummies for two-year periods are used instead. The usage of two-year periods does not alter the results for the other estimated parameters. Note,
} 


\section{Empirical estimations}

In Figure 2, the survival and hazard functions for the sample are estimated by the Lifetable method (actuarial method). The patent application year is set to 0 . The survival function falls steeply in the beginning, but after 4-5 years it levels away. The fact that the survival function equals around 0.95 at year 0 depends on that almost $5 \%$ of the inventions are commercialized before the owners have applied a patent for them. The Hazard function (conditional probability) is the highest during the first three years after the application. In Figure 3, the same survival and hazard functions are estimated, but this time the sample is divided in two groups: one with government financing and the other without. The survival function suggests that the gap increases over time and the hazard is mostly higher for patents with no government financing. The survival functions for patents with and without private venture capital are similar (not shown), and with respect to other external financing, the survival function is lower (higher commercialization rate) for those patents with no other external financing (not shown).

The AFT-model is run using three different variants in order to test for robustness: Model I with region dummies, Model 2 with technology dummies and Model III with both technology and region dummies. Furthermore, there are five different models based on the residual distributions: the exponential, Weibull, loglogistic, log-normal and gamma models. Before turning to the estimated parameters of the explanatory variables, I firstly analyze goodness-of-fit of the models.

In Table 4, goodness-of-fit tests based on the log-likelihoods for the models are presented. The gamma model, which is the most general model, has the highest loglikelihood. The other models are tested against this model. As can be seen, both the exponential and Weibull models are rejected. The log-normal model seems to fit the data as good as the gamma model. The log-logistic model has a very low log-likelihood, but this model is not nested with the other ones. No test can therefore be applied.

Another way to analyze goodness-of-fit is to look at the hazard function, which is closely connected to the residual characteristics of the different models. In Figure 2, the hazard function has an inverted U-shape, which is typical for a log-normal model. Also a log-logistic model can have a hazard with an inverted U-shape, provided that the scale parameter is estimated to lower than 1. In the estimation of the log-logistic model, however, the scale parameter equals 3.4. Based on the log-likelihood and the value of

only one patent was applied in 1985 and no during the 1986-89 period. Therefore, 1985 and 1990 have been merged into one group. 
the estimated scale parameter, the log-logistic model is therefore rejected. The exponential model corresponds to a constant hazard function and the Weibull model to a monotonously declining or increasing hazard. Thus, it is not surprising that these models are rejected.

The estimations of the AFT-model are shown in Table 5. The values and the significance levels of the estimated parameters are very similar across the log-normal and gamma models for all explanatory variables. The results are also robust across Models I-III, where different dummy variables for regions and technologies are included. As expected, the estimated time it takes until commercialization starts is significantly shorter for the three firm size groups (FIRM1-FIRM3) compared to individuals. Thus, patents owned by firms have a shorter time until commercialization starts compared to patents owned by individuals, indicating that firms have more complementary financial, manufacturing and marketing capabilities. However, the difference between the three firm-groups is not significant. The quantitative interpretation of the estimated parameters in the log-normal model III is that if the firm dummies take on the value 1 instead of 0 , then the survival time decreases with 59.6, 50.9 and $61.7 \%$ for FIRM1, FIRM2 and FIRM3 compared to individuals, respectively. ${ }^{11}$

Turning to the financial variables, GOVFIN has a positive and strongly significant influence on the survival time. The quantitative interpretation of the estimated parameter in the log-normal model III is as follows: if the government financing during the R\&D-phase increases by 1 unit (in this case $1 \%$-unit), then the survival time increases by $1.51 \%$. A more accurate interpretation is, however, that the government's loan condition creates a selection bias of patents with no or bad perspectives of commercialization. It is likely that many of the inventions behind the patents would never be patented without the government assistance. The loan conditions also deter many good patents from being commercialized, since the repayment, which is connected to the turnover, erases the profit. If one regards that this selection bias would "disturb" the estimated effects of the other explanatory variables in the regressions, then it is lucky that the variable, which creates the disturbance, GOVFIN, actually is included in the estimations. It is likely that GOVFIN will take account of the pool of bad patents.

\footnotetext{
${ }^{11}$ The quantitative interpretation of the effect of the explanatory variables (also dummies) on the survival time is done in the following way. If the explanatory variable increases with 1 unit, the survival time changes with $100\left(\mathrm{e}^{\beta}-1\right) \%$.
} 
The estimated parameter of PRIVFIN has the expected negative sign, but is only significant at the $10 \%$-level in two of six runs. OTHFIN never turns out to have any significant effect. UNIV has the expected positive influence, but is surprisingly only significant at the $10 \%$-level in four of six runs. The university researchers have a commercialization rate of only $34 \%$ compared to $61 \%$ in the whole dataset. A problem is here that the typical inventor (but not all of them) who receives external financing from universities and research foundations (i.e. OTHFIN has a positive value) is a university researcher. Thus, OTHFIN and UNIV partly measure the same thing. The correlation between the two variables is 0.52 (see Appendix Table A1), not extremely strong, but maybe strong enough to disturb the estimations. In the first and second column of Table 6 , one of the two variables is alternatively excluded for the log-normal model III. UNIV is then significant at the 5\%-level and OTHFIN at the 10\%-level. However, the results for the other variables are not affected. The same result with respect to significance levels for UNIV and OTHERFIN are obtained also if Model I or II is chosen, or if the Gamma model is run instead. Thus, I conclude that university patents have a significantly longer time until commercialization starts. The quantitative interpretation of an increase from 0 to 1 for the dummy UNIV is that the time it takes until commercialization starts increases with as much as $246 \%$.

More robustness tests of the log-normal model are shown in Table 6. INVNMBR is dropped in the third and fourth columns of Table 6 and MOREPAT in the fourth column. The results of the other variables are not affected. In the fifth column of Table 6, a group of five patent strategy dummies are included compared to the main estimation in Table 5. ${ }^{12}$ These dummies show in which international regions the owners have applied for a patent. The group of dummies is highly significant. A problem with these dummy variables is, however, that they are likely to be endogenous. The choice to apply for patents in other countries almost always occurs after the patent application in the home country and is likely to be dependent on if the owners have decided to commercialize the patent or not. Therefore, not much attention is given to the estimations in the fifth column. ${ }^{13}$

\footnotetext{
${ }^{12}$ The international patent application strategies of the owners are divided into six groups: 1) World patent (PCT); 2) OECD-countries; 3) Europe (EPO); 4) USA/North America; 5) Some separate countries in Europe; and 6) No patent applications in other countries. Additive dummies are assigned to groups 1-5. ${ }^{13}$ The Weibull, exponential and logistic models were all rejected based on the likelihood-ratios tests, but GOVFIN and the firm-size dummies (FIRM1-FIRM3) have the same strong influence on the dependent variables also in these models. Furthermore, especially in the Weibull and Exponential models, PRIVFIN
} 


\section{Concluding remarks}

In the present study, a survival model was run, for the first time, to estimate how different explanatory factors affect the time it takes until patents are commercialized. A unique database on Swedish patents was used, where it is possible to observe if and when the patents were commercialized. It was especially analyzed how the financing of the $R \& D$-phase influence the probability that the patents are commercialized. This is interesting, since compared to the U.S., where the external financing occurs on a private market, Sweden has during long time relied on government support.

The most interesting conclusion from the estimations is that the larger share of the costs during the R\&D-phase that are covered by financial support by government institutions, the longer time it takes until the commercialization starts. A more accurate interpretation is that the government financing creates a pool of patents, which have few perspectives of commercialization. Many of the owners of these inventions would never apply for a patent at all, had it not been for the government support. It is likely that the bad performance of patents financed by the government depends on moral hazard problems, due to the design of the government loans. The borrower can escape from paying back the loan if the project failures. If commercialization is undertaken, repayment is connected to the turnover. This means that patents, which have a low or medium expected profit, will seldom be commercialized. Private venture capital firms, on the other hand, are repaid as a share of the profits. Thus, there is always an incentive to commercialize for the owners even if the profit is low. Another explanation to the bad performance of the government patent projects could be that the government institutions are not profit maximizing, and consequently have no incentives to find promising patent projects to lend money to.

Patents with private external financing during the R\&D-phase are commercialized at least as fast as the average, but not significantly faster. On the other hand, university patents have a significantly longer time until they are commercialized. Different sizes of firms had a strongly significant impact on the commercialization start time. Patents created in firms (medium-sized and small firms as well as close companies) are commercialized faster than patents owned by individuals, indicating

has a negative and significant parameter estimate, and UNIV a positive and significant parameter estimate, both mostly at the 5\%-level. 
how important complementary resources, like financing, marketing and manufacturing, are for commercialization.

Considering policy implications, the government should change the design of the loans. For example, the repayment should be connected to the profit of the commercialization instead of connected to the turnover. The best recommendation is, however, that the government stops to act as a venture capital firm, and does not lend any money at all. One argument for the government to intervene in the market for venture capital would be that there are market imperfections in the market for external financing. However, this does not need to be true, since private PVC-firms exist and private market solutions work well in other countries, e.g., in the U.S.

The Swedish government should instead facilitate market solutions and the growth of PVC-firms. According to Braunerhjelm (1999), the lack of private venture capital in Sweden depends on the tax system. Changes are especially urgent with respect to taxation of PVC-firms. Today, the Swedish PVC-firms are tripled taxed. First, the profits / dividends from the projects are taxed, second, there is a tax on the profit in the PVC-firm and, finally, the dividends from the PVC-firms to the owners are taxed. In close companies, the taxation rules should also be changed. A large part of the profits for active shareholders is today taxed as working incomes $(>50 \%$ marginal tax rate) instead of as capital incomes (constant 30\% marginal tax rate). A shift of the taxation towards capital incomes would mean that business angels easier and earlier could invest in different projects. Another advantage with private PVC-firms is that they not only supply financial resources, but also networks and competence in the form of marketing and management.

Finally, I give some suggestions for future research. In the present study, I have analyzed how different factors affect the choice to commercialize patents or not. There are further steps to investigate, for example, how different factors influence the performance of the commercialization. Some kind of patent projects has maybe a higher expected level of profit than others, depending on the characteristics (e.g., financing, risk, technology) of the projects. The probability of success and the expected profit given that the project is successful are other success dimensions to investigate and relate the explanatory factors with. 


\section{References}

Allison, P.D., 1995, Survival Analysis Using SAS - A Practical Guide, SAS Institute Inc., Cary, NC.

Association of University Technology Managers, 1998, AUTM Licensing Survey, Association of Technology Managers, Norwalk, CT.

Braunerhjelm, P., 1999, 'Venture capital, mångfald och tillväxt', (Venture Capital, Variety and Growth), Ekonomisk Debatt, Vol. 27, No. 4, pp. 213-22.

Breschi, S., F. Lissoni and F. Malerba, 2004, 'The Empirical Assessment of Firms' Technological Coherence: Data and Methodology', in The Economics and Management of Technological Diversification, J. Cantwell, A. Gambardella and O. Granstrand (eds.), Routledge, London.

Cohen, W.M., R.R. Nelson and J.P. Walsh, 2000, 'Protecting their Intellectual Asserts: Appropriability Conditions and why U.S. Manufacturing Firms Patent (or not)', NBER Working Paper No. 7552, NBER, Cambridge, MA.

Cox, D.R., 1972, 'Regression Models and Life Tables', Journal of Royal Statistical Society, B34, pp. 187-220.

Cutler, R.S., 1984, 'A Study of Patents Resulting from NSF Chemistry Program', World Patenting Information, Vol. 6, pp. 165-69.

EU, 2001, Towards a European Research Area. Key Figures 2001, Office for Official Publications of the European Communities, Luxemburg.

Goldfarb, B. and M. Henrekson, 2001, 'Bottom-Up vs. Top-Down Policies towards the Commercialization of University Intellectual Property', SSE/EFI Working Paper No. 463, Stockholm School of Economics, Stockholm.

Griliches, Z., 1990, 'Patent Statistics as Economic Indicators: A Survey', Journal of Economic Literature, Vol. 28, pp. 1661-1707.

Jaffe, A. and J. Lerner, 2001, 'Reinventing Public R\&D: Patent Policy and the Commercialization of National Laboratory Technologies', RAND Journal of Economics, Vol. 32, pp. 167-198.

Karaömerlioglu, D.C. and S. Jacobsson, 2000, 'Nya resultat om svensk venture capitalindustri', Ekonomisk Debatt, Vol. 28, No. 3, pp. 259-266.

Morgan, R.P., C. Kruytbosch and N. Kannankutty, 2001, 'Patenting and Invention Activity of U.S. Scientists and Engineers in the Academic Sector: Comparisons with Industry', Journal of Technology Transfer, Vol. 26, pp. 173-183.

National Science Board, 1997, Science and Engineering Indicators, USGPO, Washington DC. 
NUTEK, 1998, Småföretag och regioner i Sverige 1998 - Med ett tillväxtperspektiv för hela landet, B1998:10, NUTEK, Stockholm.

Rickne, A. and S. Jacobsson, 1996, 'New Technology-Based Firms - An Exploratory Study of Technology Exploitation and Industrial Renewal', International Journal of Technology Management, Vol. 11, pp. 238-57.

Rickne, A., and S. Jacobsson, 1999, 'New Technology-Based Firms in Sweden. A Study of Their Impact on Industrial Renewal', Economics of Innovation and New Technology, Vol. 8., pp. 197-223.

Rossman, J. and B.S. Sanders, 'The Patent Utilization Study', Patent, Trademark and Copyright Journal of Research and Education, Vol. 1, pp. 74-111.

Sanders, B.S., 1962, 'Speedy Entry of Patented Inventions into Commercial Use', Patent, Trademark and Copyright Journal of Research and Education, Vol. 6, pp. 87116.

Sanders, B.S., 1964, 'Patterns of Commercial Exploitation of Patented Inventions by Large and Small Corporations', Patent, Trademark and Copyright Journal of Research and Education, Vol. 8, pp. 51-92.

Sanders, B.S., J. Rossman and L.J. Harris, 1958, Patent, Trademark and Copyright Journal of Research and Education, Vol. 2, pp. 340-62.

Schmookler, J., 1966, Invention and Economic Growth, Harvard University Press, Cambridge.

SOU 1996:70, Samverkan mellan högskolan och näringslivet, Huvudbetänkande av NYFOR, Fritzes, Stockholm.

SRI International, 1985, NSF Engineering Program Patent Study, Menlo Park, CA.

Svensson, R., 2002, 'Commercialization of Swedish Patents: A Pilot Study in the Medical and Hygiene Sectors', IUI Working paper No. 583, IUI, Stockholm.

Utterback, J.M. and G. Reitberger, 1982, Technology and Industrial Innovation in Sweden: A Study of New-Technology Based Firms, Center for Policy Alternatives, MIT and STU, Stockholm. 
Table 1. Commercialization of patents across firm sizes and inventors' ownership, number of patents and percent.

\begin{tabular}{|c|c|c|c|c|}
\hline \multirow{3}{*}{ Kind of firm where invention was created } & \multicolumn{3}{|c|}{ Number of patents } & \multirow{3}{*}{$\begin{array}{c}\text { Percent } \\
\text { Commercialized }\end{array}$} \\
\hline & \multicolumn{2}{|c|}{ Commercialization } & \multirow[t]{2}{*}{ Total } & \\
\hline & Yes & No & & \\
\hline Medium-sized firms (101-1000 employees) & 77 & 39 & 116 & $66 \%$ \\
\hline \multirow{3}{*}{$\begin{array}{l}\text { Small firms (11-100 employees) } \\
\text { Close companies ( } 2-10 \text { employees) } \\
\text { Inventors alone (1-4 inventors) }\end{array}$} & 137 & 64 & 201 & $68 \%$ \\
\hline & 105 & 37 & 142 & $74 \%$ \\
\hline & 211 & 197 & 408 & $52 \%$ \\
\hline Total & 530 & 337 & 867 & $61 \%$ \\
\hline \multicolumn{5}{|l|}{ Inventors' ownership (directly or indirectly) } \\
\hline \multirow{2}{*}{$\begin{array}{l}\text { Owner } \\
\text { Not owner }\end{array}$} & 366 & 255 & 621 & $59 \%$ \\
\hline & 164 & 82 & 246 & $67 \%$ \\
\hline Total & 530 & 337 & 867 & $61 \%$ \\
\hline
\end{tabular}

Table 2. External financing during the R\&D-phase and commercialization, number of patents and percent.

\begin{tabular}{|c|c|c|c|c|}
\hline \multicolumn{5}{|c|}{ Any external financing } \\
\hline \multirow{2}{*}{$\begin{array}{l}\text { External financing } \\
\text { during the R\&D-phase }\end{array}$} & \multicolumn{2}{|c|}{ Commercialization } & \multirow[t]{2}{*}{ Total } & \multirow[t]{2}{*}{ Percent } \\
\hline & Yes & No & & \\
\hline No & 422 & 238 & 660 & $63.6 \%$ \\
\hline Yes & 108 & 99 & 207 & $52.2 \%$ \\
\hline Total & 530 & 337 & 867 & $61.1 \%$ \\
\hline \multicolumn{5}{|c|}{ Chi-square-test $=9.18 * *$} \\
\hline \multicolumn{5}{|c|}{ Government external financing } \\
\hline \multirow{2}{*}{$\begin{array}{l}\text { External financing } \\
\text { during the R\&D-phase }\end{array}$} & \multicolumn{2}{|c|}{ Commercialization } & \multirow[t]{2}{*}{ Total } & \multirow[t]{2}{*}{ Percent } \\
\hline & Yes & No & & \\
\hline No & 460 & 265 & 725 & $63.4 \%$ \\
\hline Yes & 70 & 72 & 142 & $49.3 \%$ \\
\hline Total & 530 & 337 & 867 & $61.1 \%$ \\
\hline \multicolumn{5}{|c|}{ Chi-square $=10.01 * * *$} \\
\hline \multicolumn{5}{|c|}{ Private external financing } \\
\hline \multirow{2}{*}{$\begin{array}{l}\text { External financing } \\
\text { during the R\&D-phase }\end{array}$} & \multicolumn{2}{|c|}{ Commercialization } & \multirow[t]{2}{*}{ Total } & \multirow[t]{2}{*}{ Percent } \\
\hline & Yes & No & & \\
\hline No & 500 & 319 & 819 & $61.1 \%$ \\
\hline Yes & 30 & 18 & 48 & $62.5 \%$ \\
\hline Total & 530 & 337 & 867 & $61.1 \%$ \\
\hline \multicolumn{5}{|c|}{ Chi-square $=0.04$} \\
\hline \multicolumn{5}{|c|}{ Other external financing (e.g., universities, research foundations) } \\
\hline \multirow{2}{*}{$\begin{array}{l}\text { External financing } \\
\text { during the R\&D-phase }\end{array}$} & \multicolumn{2}{|c|}{ Commercialization } & \multirow[t]{2}{*}{ Total } & \multirow[t]{2}{*}{ Percent } \\
\hline & Yes & No & & \\
\hline No & 489 & 305 & 794 & $61.6 \%$ \\
\hline Yes & 41 & 32 & 73 & $56.2 \%$ \\
\hline Total & 530 & 337 & 867 & $61.1 \%$ \\
\hline \multicolumn{5}{|c|}{ Chi-square $=0.83$} \\
\hline
\end{tabular}

Note: 207 patents have external financing, but some patents have external financing from more than one source. ("patfin1.sas") 
Table 3. Descriptive statistics and hypotheses for the explanatory variables.

\begin{tabular}{|c|c|c|c|c|}
\hline Denotation & Description & Mean & $\begin{array}{c}\text { St.dev } \\
.\end{array}$ & $\begin{array}{l}\text { Impact on } \\
\text { survival time }\end{array}$ \\
\hline FIRM1 & $\begin{array}{l}\text { Dummy taking the value of } 1 \text { for medium-sized } \\
\text { firms (101-1000 employees), and } 0 \text { otherwise. }\end{array}$ & 0.13 & 0.34 & - \\
\hline FIRM2 & $\begin{array}{l}\text { Dummy taking the value of } 1 \text { for small firms (11-100 } \\
\text { employees), and } 0 \text { otherwise. }\end{array}$ & 0.23 & 0.42 & - \\
\hline FIRM3 & $\begin{array}{l}\text { Dummy taking the value of } 1 \text { for close companies (2- } \\
10 \text { employees), and } 0 \text { otherwise. }\end{array}$ & 0.16 & 0.37 & - \\
\hline GOVFIN & Percent of R\&D financed by government. & 7.69 & 21.1 & + \\
\hline PRIVFIN & Percent of R\&D financed by private venture capital. & 3.14 & 14.4 & - \\
\hline OTHFIN & $\begin{array}{l}\text { Percent of R\&D financed by universities / research } \\
\text { foundations }\end{array}$ & 2.73 & 14.4 & + \\
\hline UNIV & $\begin{array}{l}\text { Dummy that equals } 1 \text { if the patent was created at a } \\
\text { university, and } 0 \text { otherwise. }\end{array}$ & 0.04 & 0.19 & + \\
\hline OWNER & $\begin{array}{l}\text { Percent of the patent that is directly or indirectly } \\
\text { owned by the inventors. }\end{array}$ & 65.2 & 45.2 & - \\
\hline MOREPAT & $\begin{array}{l}\text { Dummy taking the value of } 1 \text { if the inventors have } \\
\text { more similar (competitive) patents. }\end{array}$ & 0.41 & 0.49 & $?$ \\
\hline INVNMBR & Number of inventors of the patent. & 1.34 & 0.66 & $?$ \\
\hline
\end{tabular}

Table 4. Goodness-of-fit tests with Likelihood-ratio statistic.

\begin{tabular}{|l|l|l|c|c|}
\hline \hline Model & Log-likelihood & Test between models & d.f. & $\begin{array}{c}\text { Likelihood-ratio } \\
\text { Chi-square statistics }\end{array}$ \\
\hline Exponential & -1659.37 & Exponential vs. Weibull & 1 & $157.06 * * *$ \\
Weibull & -1580.84 & Exponential vs. Gamma & 2 & $184.04 * * *$ \\
Log-logistic & -1925.08 & Weibull vs. Gamma & 1 & $26.98 * * *$ \\
Log-normal & -1567.44 & Log-normal vs. Gamma & 1 & 0.18 \\
Gamma & -1567.35 & & & \\
\hline
\end{tabular}

Note: The log-likelihoods are taken from Model III. ***,** and * indicate significance at the 1, 5 and $10 \%$ level, respectively. The same conclusion with respect to significance of the tests would be done, if log-likelihoods from Models I or II are used. The log-logistic model is not nested with the other models. 
Table 5. Empirical estimations of the AFT-model.

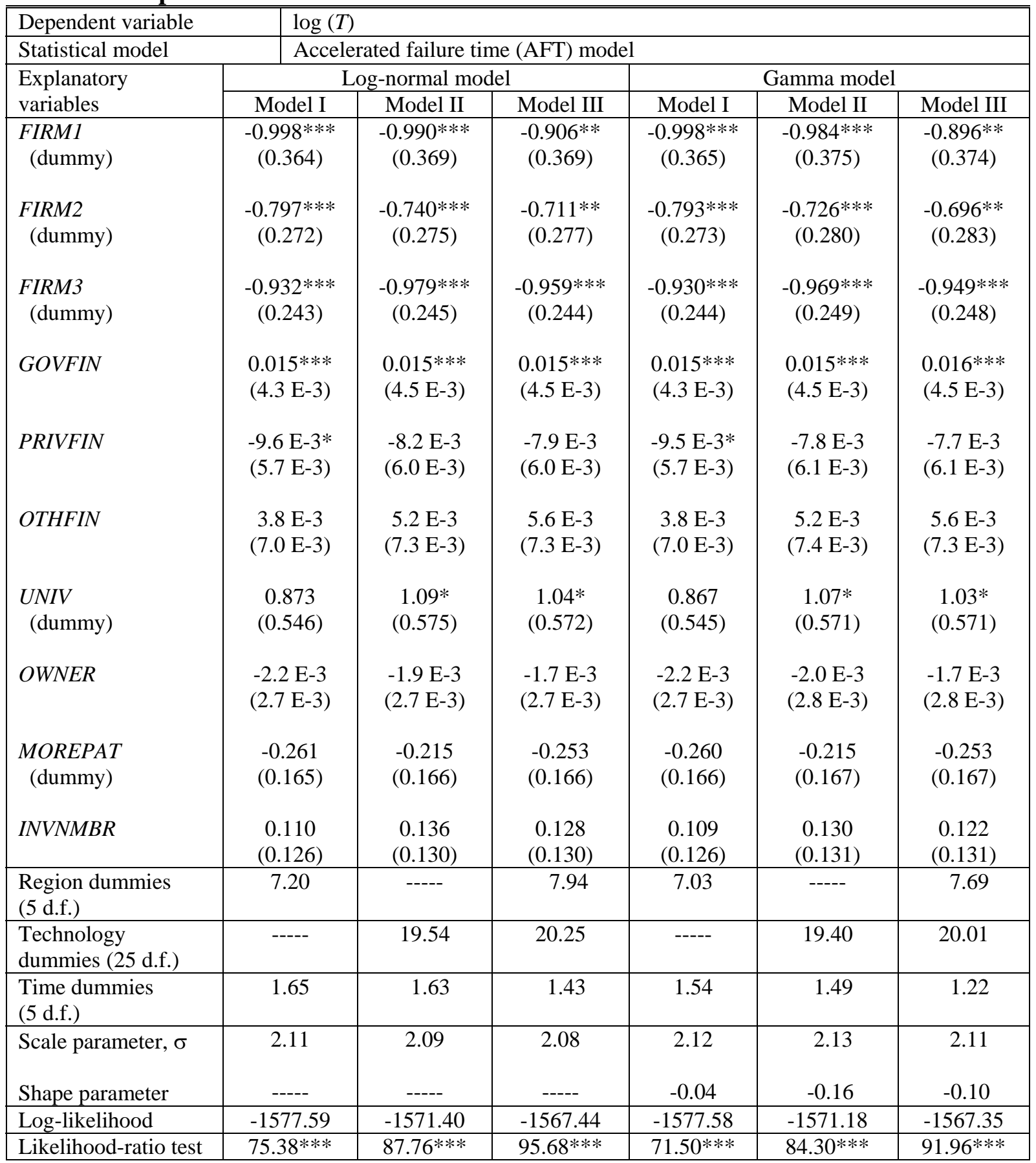

Note: The total number of observations equals 867 , of which 37 are left-censored observations, 493 interval-censored, and 337 right-censored. Standard errors are in parentheses and $* * *, * *$ and $*$ indicate significance at the 1,5 and 10\% level, respectively. For the region, technology and time dummies, only Wald chi-square values (never significant) for the whole group of dummies are shown. Intercepts as well as individual region, technology and time dummies are available from the author on request. 
Table 6. Robustness tests of the AFT-model, log-normal model.

\begin{tabular}{|c|c|c|c|c|c|}
\hline \multirow{2}{*}{$\begin{array}{l}\text { Dependent variable } \\
\text { Statistical model }\end{array}$} & \multicolumn{2}{|c|}{$\log (T)$} & & & \\
\hline & \multicolumn{3}{|c|}{ Accelerated failure time (AFT) model } & & \\
\hline \multirow{2}{*}{$\begin{array}{l}\text { Explanatory } \\
\text { variables }\end{array}$} & \multicolumn{5}{|c|}{ Log-normal model } \\
\hline & Model III & Model III & Model III & Model III & Model III \\
\hline $\begin{array}{l}\text { FIRM1 } \\
\text { (dummy) }\end{array}$ & $\begin{array}{c}-0.904 * * \\
(0.369)\end{array}$ & $\begin{array}{c}-0.993 * * * \\
(0.367)\end{array}$ & $\begin{array}{c}-0.873 * * \\
(0.368)\end{array}$ & $\begin{array}{c}-0.933^{* *} \\
(0.366)\end{array}$ & $\begin{array}{l}-0.623 * \\
(0.367)\end{array}$ \\
\hline $\begin{array}{l}\text { FIRM2 } \\
\text { (dummy) }\end{array}$ & $\begin{array}{c}-0.710 * * \\
(0.277)\end{array}$ & $\begin{array}{c}-0.789 * * * \\
(0.274)\end{array}$ & $\begin{array}{c}-0.692 * * \\
(0.276)\end{array}$ & $\begin{array}{c}-0.736 * * * \\
(0.274)\end{array}$ & $\begin{array}{l}-0.501 * \\
(0.275)\end{array}$ \\
\hline $\begin{array}{l}\text { FIRM3 } \\
\text { (dummy) }\end{array}$ & $\begin{array}{c}-0.966^{* * * *} \\
(0.244)\end{array}$ & $\begin{array}{c}-1.014 * * * \\
(0.243)\end{array}$ & $\begin{array}{c}-0.953 * * * \\
(0.244)\end{array}$ & $\begin{array}{c}-0.988 * * * \\
(0.244)\end{array}$ & $\begin{array}{c}-0.777 * * * \\
(0.243)\end{array}$ \\
\hline GOVFIN & $\begin{array}{l}0.015 * * * \\
(4.5 \mathrm{E}-3)\end{array}$ & $\begin{array}{l}0.016^{* * * *} \\
(4.5 \mathrm{E}-3)\end{array}$ & $\begin{array}{l}0.015 * * * \\
(4.5 \mathrm{E}-3)\end{array}$ & $\begin{array}{l}0.016 * * * \\
(4.3 \mathrm{E}-3)\end{array}$ & $\begin{array}{l}0.015 * * * \\
(4.5 \mathrm{E}-3)\end{array}$ \\
\hline PRIVFIN & $\begin{array}{l}-8.2 \mathrm{E}-3 \\
(6.0 \mathrm{E}-3)\end{array}$ & $\begin{array}{l}-6.5 \mathrm{E}-3 \\
(5.9 \mathrm{E}-3)\end{array}$ & $\begin{array}{l}-7.6 \mathrm{E}-3 \\
(6.9 \mathrm{E}-3)\end{array}$ & $\begin{array}{l}-8.4 \mathrm{E}-3^{*} \\
(6.0 \mathrm{E}-3)\end{array}$ & $\begin{array}{l}-5.4 \mathrm{E}-3 \\
(5.9 \mathrm{E}-3)\end{array}$ \\
\hline OTHFIN & ----- & $\begin{array}{c}0.012 * \\
(6.6 \mathrm{E}-3)\end{array}$ & $\begin{array}{c}6.9 \mathrm{E}-3 \\
(7.2 \mathrm{E}-3)\end{array}$ & $\begin{array}{c}6.8 \mathrm{E}-3 \\
(7.2 \mathrm{E}-3)\end{array}$ & $\begin{array}{c}2.8 \mathrm{E}-3 \\
(7.3 \mathrm{E}-3)\end{array}$ \\
\hline $\begin{array}{l}\text { UNIV } \\
\text { (dummy) }\end{array}$ & $\begin{array}{l}1.24 * * \\
(0.512)\end{array}$ & ----- & $\begin{array}{c}1.05^{*} \\
(0.573)\end{array}$ & $\begin{array}{c}1.08 * \\
(0.572)\end{array}$ & $\begin{array}{l}1.33 * * \\
(0.568)\end{array}$ \\
\hline OWNER & $\begin{array}{l}-1.7 \mathrm{E}-3 \\
(2.7 \mathrm{E}-3)\end{array}$ & $\begin{array}{l}-2.2 \mathrm{E}-3 \\
(2.7 \mathrm{E}-3)\end{array}$ & $\begin{array}{l}-1.6 \mathrm{E}-3 \\
(2.7 \mathrm{E}-3)\end{array}$ & $\begin{array}{l}-1.6 \mathrm{E}-3 \\
(2.7 \mathrm{E}-3)\end{array}$ & $\begin{array}{l}0.03 \mathrm{E}-3 \\
(2.7 \mathrm{E}-3)\end{array}$ \\
\hline $\begin{array}{c}\text { MOREPAT } \\
\text { (dummy) }\end{array}$ & $\begin{array}{l}-0.254 \\
(0.166)\end{array}$ & $\begin{array}{l}-0.267 \\
(0.166)\end{array}$ & $\begin{array}{l}-0.246 \\
(0.166)\end{array}$ & ----- & $\begin{array}{c}0.044 \\
(0.174)\end{array}$ \\
\hline INVNMBR & $\begin{array}{c}0.145 \\
(0.128)\end{array}$ & $\begin{array}{c}0.130 \\
(0.130)\end{array}$ & ----- & ----- & $\begin{array}{c}0.125 \\
(0.128)\end{array}$ \\
\hline $\begin{array}{l}\text { Patenting strategy } \\
\text { dummies ( } 5 \text { d.f.) }\end{array}$ & ----- & ---- & ----- & ---- & $34.43 * * *$ \\
\hline $\begin{array}{l}\text { Region dummies } \\
\text { ( } 5 \text { d.f.) }\end{array}$ & 7.86 & 8.24 & 8.07 & 7.44 & 6.38 \\
\hline $\begin{array}{l}\text { Technology } \\
\text { dummies ( } 25 \text { d.f.) }\end{array}$ & 19.97 & 19.48 & 20.04 & 20.16 & 25.94 \\
\hline $\begin{array}{l}\text { Time dummies } \\
\text { ( } 5 \text { d.f. })\end{array}$ & 1.33 & 1.57 & 1.45 & 1.56 & 0.90 \\
\hline Scale parameter, $\sigma$ & 2.08 & 2.08 & 2.08 & 2.08 & 2.04 \\
\hline Log-likelihood & -1567.73 & -1569.13 & -1567.93 & -1569.02 & -1549.97 \\
\hline Likelihood-ratio test & $95.10 * * *$ & $92.30 * * *$ & $94.70 * * *$ & $92.52 * * *$ & $130.62 * * *$ \\
\hline
\end{tabular}

Note: The total number of observations equals 867, of which 37 are left-censored observations, 493 interval-censored, and 337 right-censored. Standard errors are in parentheses, and ***, ** and * indicate significance at the 1, 5 and $10 \%$ level, respectively. For the region, technology and time dummies, only Wald chi-square values (never significant) for the whole group of dummies are shown. Intercepts as well as individual region, technology and time dummies are available from the author on request. 


\section{APPENDIX}

Table A1. Pearson correlation matrix for the explanatory variables.

\begin{tabular}{|l|l|l|l|l|l|l|l|l|l|}
\hline FIRM2 & $-0.22^{* * *}$ & & & & & & & \\
\hline FIRM3 & $-0.17^{* * *}$ & $-0.24^{* * *}$ & & & & & & & \\
\hline GOVFIN & $-0.10^{* * *}$ & $-0.19^{* * *}$ & -0.03 & & & & & & \\
\hline PRIVFIN & $-0.06^{*}$ & $-0.06^{*}$ & -0.05 & $-0.06^{*}$ & & & & & \\
\hline OTHFIN & 0.02 & -0.04 & $-0.08^{* *}$ & -0.05 & $0.10^{*}$ & & & & \\
\hline UNIV & $-0.08^{* * *}$ & $-0.11^{* * *}$ & $-0.09^{* *}$ & 0.03 & $0.20^{* * *}$ & $0.53^{* * *}$ & & & \\
\hline OWNER & $-0.54^{* * *}$ & $-0.35^{* * *}$ & 0.02 & $0.20^{* * *}$ & -0.05 & -0.03 & 0.03 & & \\
\hline MOREPAT & $0.12^{* * *}$ & $0.12^{* * *}$ & 0.05 & $0.13^{* * *}$ & $0.10^{* * *}$ & -0.01 & -0.04 & $-0.19^{* * * *}$ & \\
\hline INVNMBR & $0.08^{* *}$ & 0.02 & -0.04 & 0.04 & 0.14 & $0.25^{* * *}$ & $0.14^{* * *}$ & $-0.07^{* *}$ & $0.09^{* * *}$ \\
\hline & FIRM1 & FIRM2 & FIRM3 & GOVFIN & PRIVFIN & OTHFIN & UNIV & OWNER & $\begin{array}{l}\text { OORE } \\
\text { PAT }\end{array}$ \\
\hline
\end{tabular}

Note: The number of observations equals 867 . ***, ** and * indicate significance at the 1,5 and $10 \%$ level, respectively. 
Figure 1. Application year and start of commercialization, number of patents. Number of patents

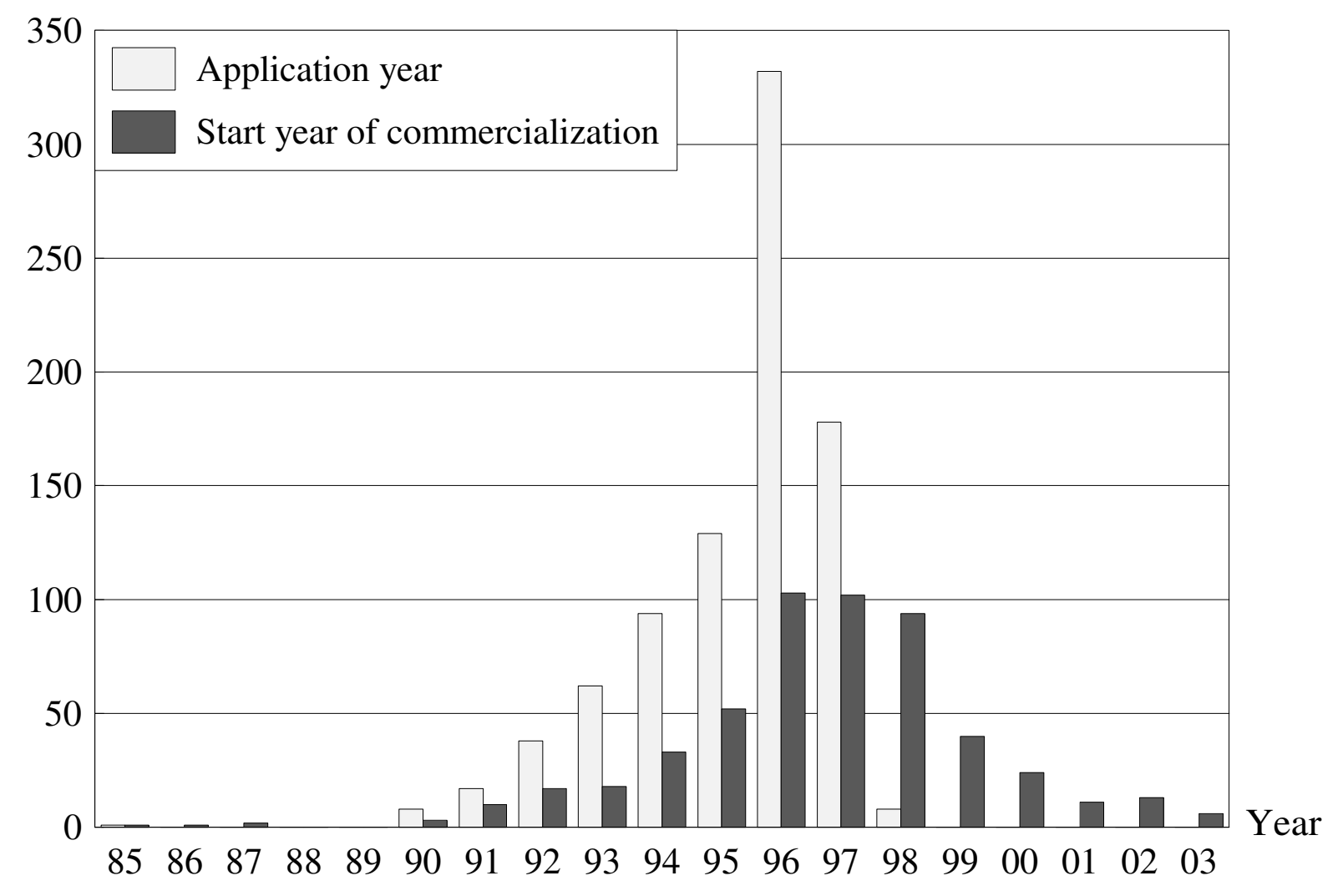


Figure 2. Survival distribution and hazard functions for Swedish patents.

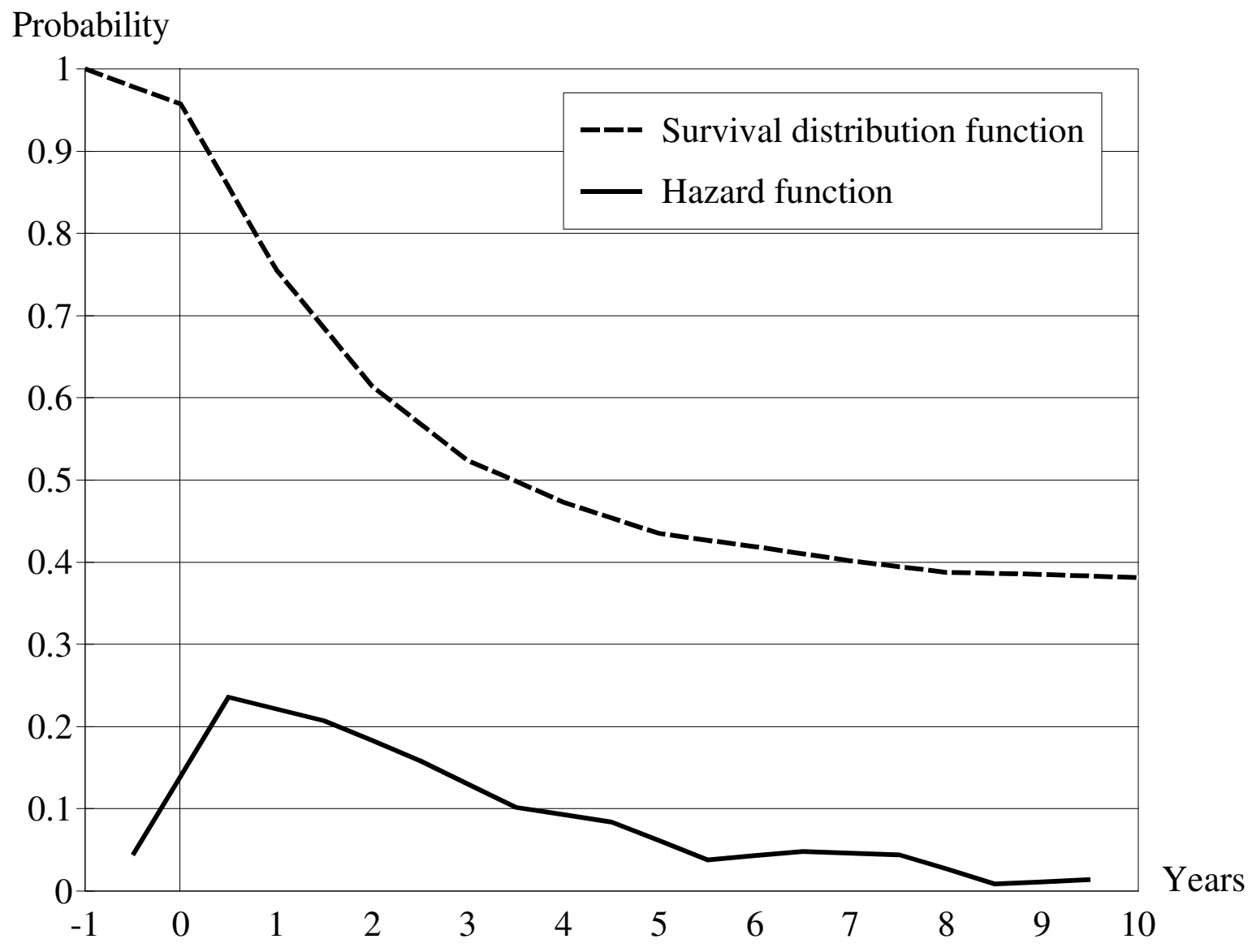


Figure 3. Survival distribution and hazard functions for Swedish patents.

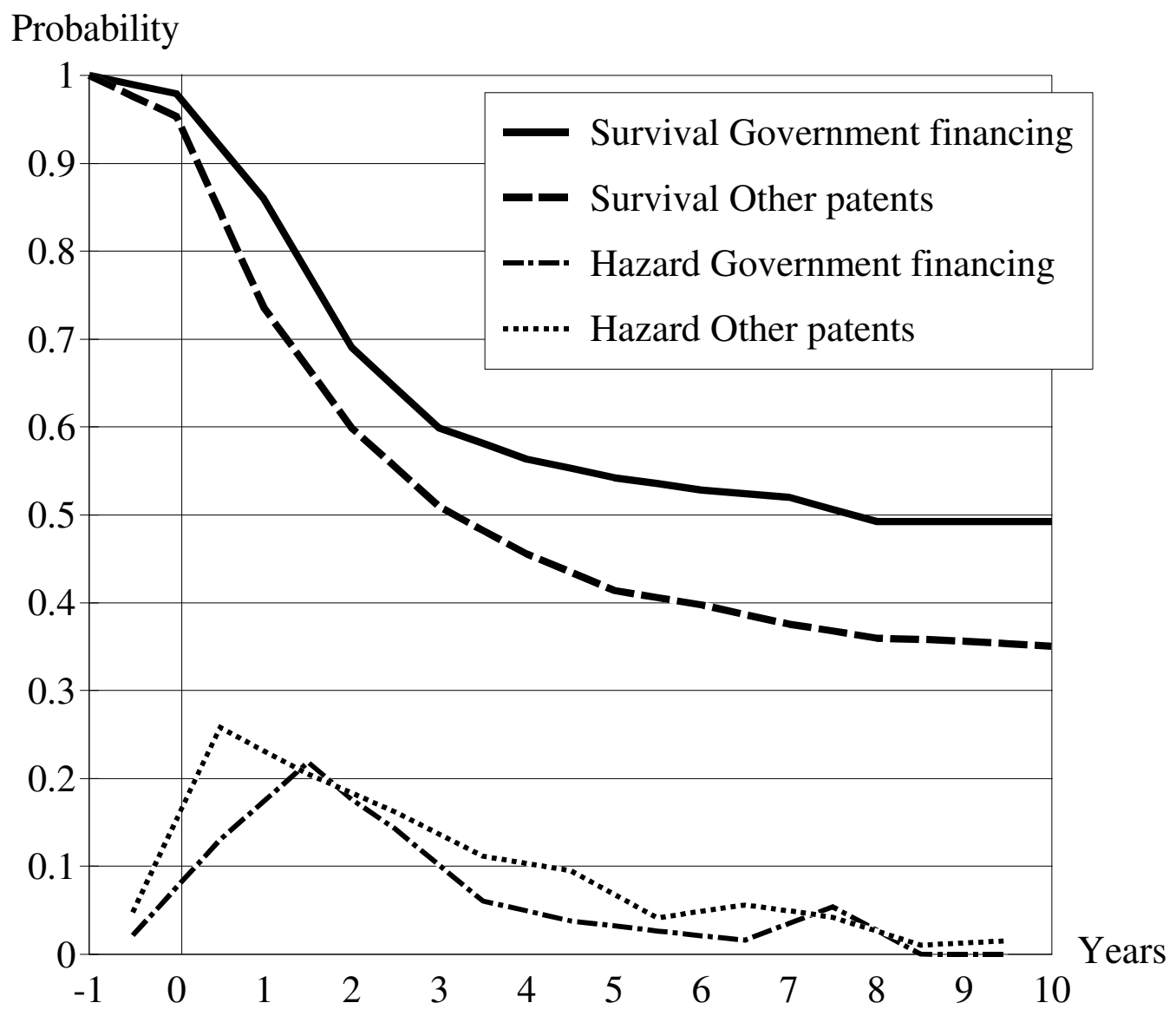

